Article

\title{
Effect of Oat Hulls Incorporated in the Diet or Fed as Free Choice on Growth Performance, Carcass Yield, Gut Morphology and Digesta Short Chain Fatty Acids of Broiler Chickens
}

\author{
Deborah Adewole * ${ }^{\mathbb{D}}$, Janice MacIsaac, Gillian Fraser and Bruce Rathgeber \\ Department of Animal Science and Aquaculture, Faculty of Agriculture, Dalhousie University, \\ Truro, NS B2N 5E3, Canada; janice.macisaac@dal.ca (J.M.); gillian.fraser@dal.ca (G.F.); brathgeber@dal.ca (B.R.) \\ * Correspondence: deborah.adewole@dal.ca; Tel.: +1-902-893-8023
}

Received: 15 April 2020; Accepted: 1 May 2020; Published: 5 May 2020

check for updates

\begin{abstract}
The use of high fiber agricultural byproducts in poultry nutrition can help not only to reduce feed cost but also to promote gastrointestinal functionality and growth performance and enhance environmental sustainability. This study was conducted to examine the effect of oat hulls $(\mathrm{OH})$ incorporated in the diet or fed as free choice on growth performance, intestinal morphology, cecal short chain fatty acids (SCFA) production and carcass yield of broiler chickens. Day old broiler chickens were assigned to 4 dietary treatment groups which consisted of a corn-soybean meal-wheat based diet (Basal), Basal + bacitracin methylene disalicylate (BMD), Basal $+3 \% \mathrm{OH}(3 \% \mathrm{OH})$ and Basal + free choice $\mathrm{OH}(\mathrm{FCOH})$. Each group had six replicate pens of 27 chicks and were raised for $39 \mathrm{~d}$. Feed intake (FI), body weight gain (BWG), and feed conversion ratio (FCR) were determined weekly for each pen. One chicken/pen was slaughtered on d 36 to determine organ weights, jejunal morphology, digesta $\mathrm{pH}$ and cecal SCFA and two chickens/pen were slaughtered on $\mathrm{d} 39$ to determine carcass weight and yield. Diet had no effect on FI, except on $d 28$, when the FCOH group had higher FI than the 3\% OH groups. During the starter phase, chickens fed 3\% OH had the highest BWG and lowest FCR, which were significantly different $(p<0.05)$ from those fed FCOH. Chickens fed $3 \% \mathrm{OH}$ had the highest slaughter, hot carcass, and cold carcass weights, which were significantly different $(p<0.05)$ from those fed FCOH. Diet had no effect on jejunal villus height and crypt depth, ileal and cecal digesta $\mathrm{pH}$, and cecal SCFA. Chickens fed FCOH had a larger $(p<0.0001)$ gizzard weight and showed a tendency to have a larger $(p=0.09)$ ceca weight than other treatment groups. In conclusion, the inclusion of $3 \% \mathrm{OH}$ in an antibiotic-free diet has the potential to enhance growth performance, while free choice $\mathrm{OH}$ increases the gizzard weight of broiler chickens.
\end{abstract}

Keywords: oat hulls; free choice; fiber; broiler chickens; growth performance; short chain fatty acids

\section{Introduction}

To preserve the potency of clinically important antibiotics, there has been a gradual reduction and an anticipated elimination of their use in food-producing animals including broiler chickens [1]. Consequently, farmers are faced with the challenge of maintaining productivity and preventing diseases on their farms [2]. Therefore, there is a need for alternative strategies including dietary means to promote gut health and growth performance of broiler chickens. High fiber ingredients have been shown to have prebiotic effects and their use in animal production could promote gut health and growth performance [3]. Oat (Avena sativa) hulls have high levels of lignin, an insoluble fiber [4,5], and have potential to modulate gastrointestinal microbiota and increase short chain fatty acids (SCFA) production, thus enhancing gut barrier integrity [3]. Short chain fatty acids have been shown to have beneficial effects on gut health 
through the interactions between diet, gut microbiota, the intestinal barrier and immunity [6]. By reducing the $\mathrm{pH}$ in the gut, SCFA helped to modify the composition of gut microbiota [6] and prevented the growth of pathogenic bacteria that are sensitive to $\mathrm{pH}$ [7]. Oat hulls $(\mathrm{OH})$ are byproducts of grain milling, which are not substantially used in the food chain, thus their use in the poultry industry could also help to reduce production costs. Many studies have reported the beneficial effects of inclusion of moderate amounts of $\mathrm{OH}$ on the growth performance of chickens. For example, an improvement in feed conversion ratio (FCR), nutrient digestibility, reduced digesta $\mathrm{pH}$, and increased gizzard weight have been observed when $2.5 \%, 3 \%, 5 \%$ or $7.5 \% \mathrm{OH}$ were fed to broiler chickens [8-10]. An improved jejunal villi surface area in chickens fed $5 \% \mathrm{OH}$ was also observed by Torki et al. [11]. There is dearth of information in the literature on the effect of $\mathrm{OH}$ on gastrointestinal SCFA. Free choice feeding of $\mathrm{OH}$ was beneficial in protecting broiler chickens against necrotic enteritis challenge [12]. However, it is not known if the beneficial effects of $\mathrm{OH}$ reported by Kheravii et al. [12] was as a result of $\mathrm{OH}$ per se or as a result of its free choice feeding. It has been shown that young broiler chickens may have a requirement for dietary fiber to optimize nutrient digestibility and growth performance [8]. This requirement is not yet known but studies have demonstrated the ability of poultry to self-select their own diets in order to meet their nutritional requirements [13]. Offering fiber ingredients as free choice to starter chicks could offer them freedom to eat just the amount needed without associated digestive disturbance. Thus, it seems possible that the free choice feeding of $\mathrm{OH}$ to broiler chickens might have more gastrointestinal benefits compared to when it is incorporated in the basal diet, but data in this field are scarce and more research is needed. No study has determined the effect of $\mathrm{OH}$ fed as free choice compared with $\mathrm{OH}$ incorporated in diets for broiler chickens, to our knowledge. The objective of this study was therefore to determine the effect of $\mathrm{OH}$ incorporated in the diet or fed as free choice on growth performance, carcass yield, organ weights, digesta $\mathrm{pH}, \mathrm{SCFA}$ production and intestinal morphology in broiler chickens.

\section{Materials and Methods}

\subsection{Ethical Approval}

The experimental procedures for this study were approved by Dalhousie University Animal Use and Care Committee and chickens were cared for in accordance with the guidelines of the Canadian Council on Animal Care [14].

\subsection{Birds and Housing}

A total of 648 day old, mixed sex broiler chickens (Ross 308) were obtained from Atlantic Poultry Inc. Port Williams, Nova Scotia. Upon arrival, chicks were weighed in groups of 27 birds and assigned to floor pens $(0.93 \mathrm{~m} \times 2.14 \mathrm{~m})$, at a stocking density of $0.076 \mathrm{~m} 2 /$ bird. Room temperature was monitored daily and was gradually reduced from 30 to $22.6^{\circ} \mathrm{C}$ from d 0 to 36 . The lighting program was set to produce 18 hours of light and 6 hours of darkness throughout the experimental period and illumination was gradually reduced from $20 \mathrm{~lx}$ on $\mathrm{d} 0$ to $5 \mathrm{~lx}$ on $\mathrm{d} 39$.

\subsection{Diets and Experimental Design}

The $\mathrm{OH}$ used in this study was obtained from Grain Millers, Yorton, Saskatchewan, Canada. They were obtained as fine particle sized (6/64 round hole and a 7/64 round hole). Four dietary treatments were assigned to 24 pens in a completely randomized design. The dietary treatments consisted of a corn-soybean meal-wheat based diet (Basal), Basal + bacitracin methylene disalicylate (BMD), Basal $+3 \% \mathrm{OH}(3 \% \mathrm{OH})$ and Basal + free choice $\mathrm{OH}(\mathrm{FCOH})$. Diets were iso-energetic and iso-nitrogenous and formulated on digestible amino acids and apparent metabolizable energy (AME) bases and met or exceeded National Research Council (NRC) [15] nutrient requirements for broiler chickens. The FCOH was provided in extra feeding troughs attached to the pens, in addition to the feeding trough that supplied the basal diet. Birds were fed using a phase-feeding program that consisted of starter phase ( $\mathrm{d} 0$ to 14), grower phase (d 14 to 22), and finisher phase (d 22 to 39). The ingredient and nutritional compositions of 
the diets in phases 1 to 3 are presented in Table 1 . The $\mathrm{OH}$ samples and diets were finely ground and were all analyzed for dry matter (DM), crude protein (CP), neutral detergent fiber (NDF), acid detergent fiber (ADF), ash, fat, and minerals. Dry matter was determined according to Association of Official Analytical Chemists (AOAC) [16] method (925.09) by oven drying a $5.0 \mathrm{~g}$ sample at $105^{\circ} \mathrm{C}$ overnight.

Table 1. Ingredient and nutrient compositions of experimental diets.

\begin{tabular}{|c|c|c|c|c|c|c|c|c|c|}
\hline \multirow{3}{*}{ Ingredient $(\%)$} & \multicolumn{9}{|c|}{ Production Period (Days of Age) } \\
\hline & \multicolumn{3}{|c|}{ 1-14 } & \multicolumn{3}{|c|}{$14-22$} & \multicolumn{3}{|c|}{$22-39$} \\
\hline & Basal & BMD & $3 \% \mathrm{OH}$ & Basal & BMD & $3 \% \mathrm{OH}$ & Basal & BMD & $3 \% \mathrm{OH}$ \\
\hline Corn & 51.08 & 50.98 & 45.43 & 44.32 & 44.22 & 38.64 & 49.12 & 49.02 & 43.62 \\
\hline Soybean Meal & 41.44 & 41.45 & 42.16 & 36.48 & 36.49 & 37.21 & 31.42 & 31.44 & 32.12 \\
\hline Wheat & - & - & - & 10.00 & 10.00 & 10.00 & 10.00 & 10.00 & 10.00 \\
\hline Oat Hulls & - & - & 3.00 & - & - & 3.00 & - & - & 3.00 \\
\hline Animal/Vegetable Fat & 2.93 & 2.97 & 4.85 & 4.59 & 4.63 & 6.52 & 5.19 & 5.22 & 6.97 \\
\hline Limestone & 1.80 & 1.80 & 1.79 & 1.65 & 1.65 & 1.64 & 1.50 & 1.50 & 1.49 \\
\hline Dicalcium Phosphate & 1.24 & 1.24 & 1.26 & 1.06 & 1.06 & 1.08 & 0.90 & 0.90 & 0.92 \\
\hline DL-Methionine Premix $\mathrm{Z}$ & 0.59 & 0.59 & 0.60 & 0.53 & 0.53 & 0.54 & 0.49 & 0.49 & 0.50 \\
\hline Lysine $\mathrm{HCl}$ & 0.01 & 0.01 & 0.01 & - & - & - & - & - & - \\
\hline Iodized Salt & 0.41 & 0.41 & 0.41 & 0.37 & 0.37 & 0.37 & 0.38 & 0.38 & 0.38 \\
\hline Pellet Binding Agent ${ }^{Y}$ & - & - & - & 0.50 & 0.50 & 0.50 & 0.50 & 0.50 & 0.50 \\
\hline BMD $110 \mathrm{G}^{\mathrm{X}}$ & - & 0.05 & - & - & 0.05 & - & - & 0.05 & - \\
\hline Vitamin/Mineral Premix W, V & 0.50 & 0.50 & 0.50 & 0.50 & 0.50 & 0.50 & 0.50 & 0.50 & 0.50 \\
\hline \multicolumn{10}{|l|}{ Calculated Composition } \\
\hline Crude Protein $(\%)$ & 23.00 & 23.00 & 23.00 & 21.50 & 21.50 & 21.50 & 19.50 & 19.50 & 19.50 \\
\hline $\begin{array}{c}\text { Metabolizable Energy } \\
\quad\left(\mathrm{kcal} \mathrm{kg}^{-1}\right)\end{array}$ & 3000 & 3000 & 3000 & 3100 & 3100 & 3100 & 3200 & 3200 & 3200 \\
\hline Calcium $(\%)$ & 0.96 & 0.96 & 0.96 & 0.87 & 0.87 & 0.87 & 0.78 & 0.78 & 0.78 \\
\hline Available Phosphorus (\%) & 0.48 & 0.48 & 0.48 & 0.44 & 0.44 & 0.44 & 0.39 & 0.39 & 0.39 \\
\hline Digestible Lysine & 1.28 & 1.28 & 1.28 & 1.16 & 1.16 & 1.17 & 1.02 & 1.02 & 1.03 \\
\hline Digestible Methionine + Cystine $(\%)$ & 0.95 & 0.95 & 0.95 & 0.87 & 0.87 & 0.87 & 0.80 & 0.80 & 0.80 \\
\hline Sodium $(\%)$ & 0.19 & 0.19 & 0.19 & 0.18 & 0.18 & 0.18 & 0.18 & 0.18 & 0.18 \\
\hline \multicolumn{10}{|l|}{ Analyzed Composition } \\
\hline Crude Protein (\%) & 23.4 & 24.6 & 23.7 & 21.9 & 22.0 & 21.8 & 19.1 & 19.8 & 21.7 \\
\hline Calcium $(\%)$ & 1.01 & 1.15 & 1.03 & 0.96 & 0.97 & 1.15 & 0.83 & 0.84 & 0.893 \\
\hline Total Phosphorus (\%) & 0.65 & 0.70 & 0.72 & 0.61 & 0.61 & 0.70 & 0.55 & 0.55 & 0.60 \\
\hline Sodium $(\%)$ & 0.19 & 0.22 & 0.19 & 0.19 & 0.19 & 0.20 & 0.17 & 0.17 & 0.17 \\
\hline Crude Fat (\%) & 6.03 & 5.71 & 7.02 & 6.91 & 6.63 & 8.03 & 8.45 & 8.36 & 9.80 \\
\hline
\end{tabular}

z Supplied/kg premix: DL-Methionine, $0.5 \mathrm{~kg}$; wheat middlings, $0.5 \mathrm{~kg} .{ }^{\mathrm{Y}}$ Pel-stik: Uniscope, Inc., Johnstown, CO, USA. ${ }^{X}$ Bacitracin methylene disalicylate (providing $55 \mathrm{mg} / \mathrm{kg}$ mixed feed); Alpharma, Inc., Fort Lee, NJ, USA. w Starter vitamin-mineral premix contained the following per kg of diet: 9750 IU vitamin A; 2000 IU vitamin D3. $25 \mathrm{IU}$ vitamin E; $2.97 \mathrm{mg}$ vitamin K; $7.6 \mathrm{mg}$ riboflavin; $13.5 \mathrm{mg}$ Dl Ca-pantothenate; $0.012 \mathrm{mg}$ vitamin B12; $29.7 \mathrm{mg}$ niacin; $1.0 \mathrm{mg}$ folic acid, $801 \mathrm{mg}$ choline; $0.3 \mathrm{mg}$ biotin; $4.9 \mathrm{mg}$ pyridoxine; $2.9 \mathrm{mg}$ thiamine; $70.2 \mathrm{mg}$ manganese; $80.0 \mathrm{mg}$ zinc; $25 \mathrm{mg}$ copper; $0.15 \mathrm{mg}$ selenium; $50 \mathrm{mg}$ ethoxyquin; $1543 \mathrm{mg}$ wheat middlings; $500 \mathrm{mg}$ ground limestone. ${ }^{\mathrm{v}}$ Grower and Finisher vitamin-mineral premix contained the following per kg of diet: $9750 \mathrm{IU}$ vitamin A; $2000 \mathrm{IU}$ vitamin D3; $25 \mathrm{IU}$ vitamin E; $2.97 \mathrm{mg}$ vitamin K; $7.6 \mathrm{mg}$ riboflavin; $13.5 \mathrm{mg}$ Dl Ca-pantothenate; $0.012 \mathrm{mg}$ vitamin B12; $29.7 \mathrm{mg}$ niacin; $1.0 \mathrm{mg}$ folic acid, $801 \mathrm{mg}$ choline;0. $3 \mathrm{mg}$ biotin; $4.9 \mathrm{mg}$ pyridoxine; $2.9 \mathrm{mg}$ thiamine; $70.2 \mathrm{mg}$ manganese; $80.0 \mathrm{mg}$ zinc; $25 \mathrm{mg}$ copper; $0.15 \mathrm{mg}$ selenium; $50 \mathrm{mg}$ ethoxyquin; $1543 \mathrm{mg}$ wheat middlings; $500 \mathrm{mg}$ ground limestone.

The method of Goering and Van Soest [17] was used for the determination of NDF and ADF. Nitrogen content in $\mathrm{OH}$ and diet samples was determined using the combustion method (990.03) [16] with an N analyzer (Model Leco CN828 Carbon Nitrogen Determinator, St. Joseph, MO) and CP was calculated as $N \times 6.25$. The ether extract in samples was determined after hexane extraction (Method 920.39) [16] in an Ankom XT10 Fat Extractor system (Macedon, NY). Samples were analyzed for minerals ( $\mathrm{Ca}, \mathrm{Na}, \mathrm{K}, \mathrm{Mg}, \mathrm{p}, \mathrm{Mn}$ and $\mathrm{Zn}$ ) after they were ashed at $600{ }^{\circ} \mathrm{C}$ for $12 \mathrm{~h}$ in a muffle furnace, using a Varian 725 ICP-OES inductively coupled plasma mass spectrometer (ICP-AES; Vista, Varian, Palo Alto, CA) according to the method of AOAC [18] (method 985.01). The analyzed composition of $\mathrm{OH}$ used in the study was presented in Table 2. 
Table 2. Chemical composition of oat hulls.

\begin{tabular}{cc}
\hline Item & Oat Hulls (Dry Matter Basis) \\
\hline Crude protein (\%) & 2.75 \\
Neutral detergent fiber (\%) & 76.5 \\
Acid detergent fiber (\%) & 44.1 \\
Digestible energy (Mcal/kg) & 2.31 \\
Calcium (\%) & 0.08 \\
Potassium (\%) & 0.35 \\
Magnesium (\%) & 0.09 \\
Phosphorus (\%) & 0.07 \\
Manganese (ppm) & 26.9 \\
Zinc (ppm) & 7.58 \\
\hline
\end{tabular}

\subsection{Measurements and Sampling}

Body weight (BW) and feed intake (FI) were determined weekly on a pen basis and mortality was recorded daily to calculate body weight gain (BWG), and FCR. Intake of $\mathrm{OH}$ for the FCOH group was also measured weekly and used in the calculation of FI and FCR. On d 36, one chicken was randomly selected from each pen, individually weighed and euthanized by electrical stunning and exsanguination. After slaughter, liver, spleen, gizzard, bursa of Fabricius, ceca, and the entire intestines were removed and weighed by trained personnel. The length of the entire intestine was measured. Digesta from ileum and ceca were collected separately and their $\mathrm{pH}$ values were determined (Oakton ${ }^{\mathrm{TM}}$ Waterproof Big Display pHTestr ${ }^{\mathrm{TM}}$ 30, Fisher Scientific). Digesta from ceca was collected and stored in plastic sterile tubes, placed in liquid nitrogen and stored at $-80^{\circ} \mathrm{C}$ for analysis of SCFA. Necrotic lesions in the intestinal tract were graded according to the procedure of Shojadoost et al. [19] as follows: zero-no gross lesions; one-thin-walled or friable small intestine; two-focal necrosis or ulceration; three-larger patches of necrosis; and four-severe, extensive necrosis typical of field cases. The jejunum was taken distally from the pancreatic loop to Meckel's diverticulum and a sample of $0.5 \mathrm{~cm}$ in length was taken from the center and placed in 10\% buffered formalin for histological measurements. For processing, these samples were placed in acetic acid/ethanol $(25 / 75, \mathrm{v} / \mathrm{v})$, for $24 \mathrm{~h}$, rehydrated in a bath of ethanol/water $(50 / 50, \mathrm{v} / \mathrm{v})$ and finally in distilled water. On d 39, two male birds per pen were slaughtered after subjection to $12 \mathrm{~h}$ fasting. Birds were individually weighed before electrical stunning, bled for 3 minutes after carotid and jugular veins were cut, scalded at $60^{\circ} \mathrm{C}$ for $90 \mathrm{~s}$, and mechanically defeathered. Carcasses were manually eviscerated and then chilled at $4{ }^{\circ} \mathrm{C}$ for $3 \mathrm{~h}$ before processing. Carcasses were weighed before and after chilling to determine hot and cold carcass weights as well as weights of breast muscle.

\subsection{Analysis of Short Chain Fatty Acids}

Cecal digesta samples were homogenized in an ethanol/20 $\mathrm{mM}$ phosphate buffer (85/15) buffer at a concentration of $1 \mathrm{mg}$ sample/ $3 \mu \mathrm{L}$ of buffer using a Precellys bead homogenizer $(3 \times 20 \mathrm{~s}$ at $5500 \mathrm{rpm}$ with a $30 \mathrm{~s}$ pause between steps). The homogenization tubes were centrifuged at $4{ }^{\circ} \mathrm{C}$ for $10 \mathrm{~m}$ at $800 \times g$ and the supernatant transferred to $1.5 \mathrm{~mL}$ tubes. These tubes were then centrifuged at $4{ }^{\circ} \mathrm{C}$ for $10 \mathrm{~m}$ at $20,000 \times g$ and the supernatant transferred to a new set of $1.5 \mathrm{~mL}$ tubes. $25 \mu \mathrm{L}$ of cecal digesta sample was taken for analysis; the equivalent of $8.33 \mathrm{mg}$ of sample. Each sample tube had $25 \mu \mathrm{L}$ of sample added followed by $20 \mu \mathrm{L}$ of internal standard mixture $(2000 \mathrm{ng} / 20 \mu \mathrm{L}$ each of acetic acid-d4 and butyric acid-d7). A standard curve from 20 to 100,000 ng each of acetic acid, propionic acid, and butyric acid was also prepared. Samples and standards were treated to the same extraction conditions as follows: each tube had $75 \mu \mathrm{L}$ of water added followed by acidification with $1 \mathrm{M} \mathrm{HCl}$ and immediate addition of $200 \mu \mathrm{L}$ of methyl-tert-butylether. Tubes were vortexed for $1 \mathrm{~min}$ on a multi-tube vortexer and then centrifuged at $4{ }^{\circ} \mathrm{C}$ for $10 \mathrm{~m}$ at $20,000 \times g$. The supernatant was transferred to an auto sampler vial with an insert and injected for analysis by GC-MS.

\subsection{Measurement of Jejunal Morphology}

The specimens of mid jejunum were embedded in paraffin, sectioned $(5 \mu \mathrm{m})$, and stained with Alcian blue ( $\mathrm{pH}$ 2.5) according to the procedures of Shang et al. (2015). Morphological measurement of villus 
height, crypt depth, and total mucosal thickness was conducted using an image processing and analysis system (ImageJ, WI, USA). The ratio of villus height to crypt depth was calculated by dividing the villus height with the crypt depth. The total mucosal thickness was measured as the entire mucosal length (Villus height + crypt depth).

\subsection{Statistical Analyses}

A one-way analysis of variance was carried out using the mixed procedure of Statistical Analysis System (SAS) with treatments Basal, $\mathrm{BMD}, 3 \% \mathrm{OH}$ or $\mathrm{FCOH}$ as factors and the following parameters as variables: feed intake, body weight gain, feed conversion ratio, jejunal morphology, digesta $\mathrm{pH}$, organ weights, carcass characteristics, and concentrations of SCFA. A normal probability plot of residuals was used to ascertain the normality of all datasets in the same statistical package. Following ANOVA, differences between significant means were tested using Tukey's honestly significant difference (HSD) test in the same statistical package. Analyzed data were presented as means, standard error of the means (SEM) and probability values. Values were considered statistically different at $p \leq 0.05$ and considered as trend at $p<0.1$.

\section{Results}

\subsection{Effect of Oat Hulls on Growth Performance and Carcass Yield}

As presented in Table 3, there was no effect of dietary treatment on FI except on $\mathrm{d} 28$ when birds that had access to $\mathrm{FCOH}$ had higher FI compared to those fed 3\% OH, while those fed basal and BMD diets were intermediate. On d 8 and 36, the BWG of birds fed Basal, BMD and 3\% OH was not different but was significantly higher than those fed FCOH. On d 15, birds fed FCOH had lower BWG than those fed $3 \% \mathrm{OH}$. For the overall BWG, FCOH was significantly lower than BMD and $3 \% \mathrm{OH}$ but not different from the basal diet. Between d 22 and 28 birds fed FCOH had higher feed intake than those fed $3 \% \mathrm{OH}$. On $\mathrm{d} 8$ and 15, the lowest (best) FCR was observed for birds fed $3 \% \mathrm{OH}$, while the highest was recorded for those fed FCOH. However, FCOH significantly increased $(p<0.05)$ FCR only during the grower and finisher phases. As illustrated in Table 4, among the birds slaughtered on d 39, those fed 3\% OH had the highest hot carcass, cold carcass and breast muscle weights, which were significantly different from those fed the $\mathrm{FCOH}$. However, there was no difference in carcass yield among treatments.

Table 3. Effect of oat hulls on growth performance of broiler chickens.

\begin{tabular}{|c|c|c|c|c|c|c|}
\hline \multirow{2}{*}{ Item } & \multicolumn{4}{|c|}{ Treatment $^{1}$} & \multirow{2}{*}{$p$-Value } & \multirow{2}{*}{ SEM } \\
\hline & Basal & BMD & $3 \% \mathrm{OH}$ & FCOH & & \\
\hline \multicolumn{7}{|l|}{ ADFI (g/bird) ${ }^{a}$} \\
\hline $1-8$ & 182 & 178 & 168 & 179 & 0.8160 & 11.3 \\
\hline $8-15$ & 365 & 362 & 343 & 366 & 0.0520 & 6.12 \\
\hline $15-22$ & 649 & 632 & 642 & 682 & 0.3286 & 19.4 \\
\hline $22-28$ & $820^{a b}$ & $818^{a b}$ & $774^{\mathrm{b}}$ & $907^{\mathrm{a}}$ & 0.0160 & 26.6 \\
\hline $28-36$ & 1427 & 1391 & 1440 & 1434 & 0.9493 & 64.7 \\
\hline $1-36$ & 3443 & 3381 & 3368 & 3567 & 0.2323 & 72.9 \\
\hline \multicolumn{6}{|l|}{ BWG (g/bird) } & - \\
\hline $1-8$ & $125^{\mathrm{a}}$ & $127^{\mathrm{a}}$ & $130^{\mathrm{a}}$ & $111^{\mathrm{b}}$ & 0.0007 & 2.82 \\
\hline $8-15$ & $388^{a b}$ & $393^{a b}$ & $400^{\mathrm{a}}$ & $362^{b}$ & 0.0192 & 7.97 \\
\hline $15-22$ & $493^{\mathrm{ab}}$ & $512^{\mathrm{a}}$ & $493^{a b}$ & $470^{\mathrm{b}}$ & 0.0356 & 9.53 \\
\hline $22-28$ & 537 & 525 & 524 & 505 & 0.1875 & 10.1 \\
\hline $28-36$ & $1437^{\mathrm{a}}$ & $1439^{a}$ & $1449^{a}$ & $1364^{b}$ & 0.0479 & 22.1 \\
\hline $1-36$ & $2317^{\mathrm{ab}}$ & $2343^{a}$ & $2346^{\mathrm{a}}$ & $2195^{b}$ & 0.0126 & 33.1 \\
\hline \multicolumn{7}{|l|}{ FCR } \\
\hline $1-8$ & 1.45 & 1.41 & 1.29 & 1.61 & 0.1362 & 0.09 \\
\hline $8-15$ & $0.94^{\mathrm{ab}}$ & $0.92^{\mathrm{ab}}$ & $0.86^{b}$ & $1.02^{\mathrm{a}}$ & 0.0032 & 0.03 \\
\hline $15-22$ & $1.32^{\mathrm{b}}$ & $1.24^{\mathrm{b}}$ & $1.29^{b}$ & $1.45^{\mathrm{a}}$ & 0.0016 & 0.03 \\
\hline $22-28$ & $1.53^{b}$ & $1.56^{\mathrm{b}}$ & $1.48^{b}$ & $1.80^{\mathrm{a}}$ & 0.0009 & 0.05 \\
\hline $28-36$ & 0.99 & 0.97 & 0.99 & 1.05 & 0.6089 & 0.04 \\
\hline $1-36$ & $1.49^{b}$ & $1.44^{\mathrm{b}}$ & $1.44^{\mathrm{b}}$ & $1.63^{\mathrm{a}}$ & 0.0001 & 0.03 \\
\hline
\end{tabular}

${ }^{1}$ Basal diet (Basal); antibiotic diet (BMD); fine oat hulls incorporated in the diet at 3\% (3\% OH); free choice oat hulls $(\mathrm{FCOH})$. In a row, means assigned different lowercase letters are significantly different, $p<0.05$ (Tukey's procedure). Standard error of the mean (SEM). ${ }^{a}$ Average daily feed intake includes oat hulls consumption; ${ }^{\mathrm{b}}$ Amount of oat hulls consumed for 36 days. 
Table 4. Effect of oat hulls on carcass weight and yield of broiler chickens (d 39).

\begin{tabular}{|c|c|c|c|c|c|c|}
\hline \multirow{2}{*}{ Item } & \multicolumn{4}{|c|}{ Treatment $^{1}$} & \multirow{2}{*}{$p$-Value } & \multirow{2}{*}{ SEM } \\
\hline & Basal & BMD & $3 \% \mathrm{OH}$ & FCOH & & \\
\hline \multicolumn{7}{|c|}{ Weight $(\mathrm{kg})$} \\
\hline Hot carcass & $2058^{a b}$ & $2042^{a b}$ & $2220^{a}$ & $1938^{\mathrm{b}}$ & 0.0524 & 69.78 \\
\hline Cold carcass & 1949 ab & $2013^{a b}$ & $2148^{\mathrm{a}}$ & $1883^{\mathrm{b}}$ & 0.0477 & 66.66 \\
\hline Breast muscle & $567.7^{\mathrm{ab}}$ & $522.8^{\mathrm{b}}$ & $633.2^{\mathrm{a}}$ & $538.1^{a b}$ & 0.0371 & 27.84 \\
\hline \multicolumn{7}{|c|}{ Yield (\% live weight) } \\
\hline Hot carcass & 73.5 & 71.9 & 73.0 & 73.0 & 0.5661 & 0.929 \\
\hline Cold carcass & 69.6 & 70.8 & 70.5 & 69.9 & 0.2642 & 0.458 \\
\hline Breast muscle & 20.2 & 18.5 & 20.8 & 20.1 & 0.2643 & 0.832 \\
\hline
\end{tabular}

${ }^{1}$ Basal diet (Basal); antibiotic diet (BMD); fine oat hulls incorporated in the diet at 3\% (3\% OH); free choice oat hulls (FCOH). In a row, means assigned different lowercase letters are significantly different, $p<0.05$ (Tukey's procedure). Standard error of the mean (SEM).

\subsection{Effect of Oat Hulls on Intestinal Parameters}

As presented in Table 5, there was no significant difference among treatments in the relative weights of spleen, liver, bursa, pancreas and entire intestine. Birds that had access to $\mathrm{FCOH}$ had higher $(p<0.0001)$ gizzard relative weight and showed a tendency $(p=0.0900)$ to have higher cecal weight, compared to the other treatment groups. There was no significant difference among treatments in intestinal length and necrotic enteritis score. However, birds fed BMD had a numerically lower score (0.33) than those on other treatments $(0.83-0.92)(p=0.1938)$. As shown in Table 6, there were no significant differences among treatments in villus height, crypt depth villus height to crypt depth ratio and total mucosal thickness. As illustrated in Table 7, there was no effect of treatment on ileal and ceca $\mathrm{pH}$ and concentrations of SCFA.

Table 5. Effect of oat hulls on relative organ weights, intestinal length and necrotic enteritis lesion in broiler chickens (d 36).

\begin{tabular}{|c|c|c|c|c|c|c|}
\hline \multirow{2}{*}{ Item } & \multicolumn{4}{|c|}{ Treatment $^{1}$} & \multirow{2}{*}{$p$-Value } & \multirow{2}{*}{ SEM } \\
\hline & Basal & BMD & $3 \% \mathrm{OH}$ & FCOH & & \\
\hline Slaughter weight (kg) & 2.55 & 2.67 & 2.55 & 2.44 & 0.1160 & 0.07 \\
\hline Spleen (g/kgBW) & 0.84 & 0.90 & 0.89 & 0.79 & 0.4968 & 0.06 \\
\hline Liver $(\mathrm{g} / \mathrm{kgBW})$ & 19.4 & 19.6 & 20.1 & 19.4 & 0.6270 & 0.44 \\
\hline Bursa (g/kgBW) & 1.67 & 1.69 & 1.79 & 1.85 & 0.8419 & 0.16 \\
\hline Pancreas (g/kgBW) & 2.51 & 2.41 & 2.68 & 2.58 & 0.5952 & 0.14 \\
\hline Gizzard (g/kgBW) & $19.6^{\mathrm{b}}$ & $19.9^{b}$ & $20.0^{b}$ & $24.6^{\mathrm{a}}$ & $<0.0001$ & 0.71 \\
\hline Ceca (g/kgBW) & 6.44 & 5.62 & 6.31 & 7.43 & 0.0900 & 0.49 \\
\hline Intestine (g/kgBW) & 48.3 & 45.9 & 48.8 & 47.8 & 0.2737 & 1.11 \\
\hline Intestinal length $(\mathrm{cm})$ & 198 & 204 & 202 & 192 & 0.1294 & 3.59 \\
\hline Necrotic lesion score & 0.83 & 0.33 & 0.92 & 0.83 & 0.1938 & 0.21 \\
\hline
\end{tabular}

${ }^{1}$ Basal diet (Basal); antibiotic diet (BMD); fine oat hulls incorporated in the diet at 3\% (3\% OH); free choice oat hulls (FCOH). In a row, means assigned different lowercase letters are significantly different, $p<0.05$ (Tukey's procedure). Standard error of the mean (SEM).

Table 6. Effect of oat hulls on jejunal morphology of broiler chickens (d 36).

\begin{tabular}{|c|c|c|c|c|c|c|}
\hline \multirow{2}{*}{ Item } & \multicolumn{4}{|c|}{ Treatment $^{1}$} & \multirow{2}{*}{$p$-Value } & \multirow{2}{*}{ SEM } \\
\hline & Basal & BMD & $3 \% \mathrm{OH}$ & FCOH & & \\
\hline Villus height, $\mathrm{mm}$ & 1.62 & 1.89 & 1.67 & 1.63 & 0.8364 & 0.238 \\
\hline Crypt depth, mm & 0.40 & 0.50 & 0.38 & 0.42 & 0.3818 & 0.049 \\
\hline $\begin{array}{l}\text { Villus height: } \\
\text { Crypt depth }\end{array}$ & 4.22 & 4.33 & 4.64 & 4.08 & 0.8609 & 0.477 \\
\hline $\begin{array}{l}\text { Total mucosal } \\
\text { thickness, mm }\end{array}$ & 2.08 & 2.52 & 2.07 & 2.05 & 0.6291 & 0.298 \\
\hline
\end{tabular}

${ }^{1}$ Basal = basal diet; $\mathrm{BMD}=$ antibiotic diet; $3 \% \mathrm{OH}=$ fine oat hulls incorporated in the diet at 3\%; and FCOH $=$ free choice oat hulls. SEM $=$ standard error of the mean. 
Table 7. Effect of oat hulls on digesta $\mathrm{pH}$ and concentrations of short chain fatty acids in broiler chickens (d 36).

\begin{tabular}{ccccccc}
\hline \multirow{2}{*}{ Item } & \multicolumn{9}{c}{ Treatment $^{\mathbf{1}}$} & \multirow{2}{*}{$\boldsymbol{p}$-Value } & \multirow{2}{*}{ SEM } \\
\cline { 2 - 5 } & Basal & BMD & $\mathbf{3 \%} \mathbf{~ O H}$ & FCOH & & \\
\hline & \multicolumn{7}{c}{ Digesta $\mathrm{pH}$} \\
Cecal pH & 6.63 & 6.42 & 6.68 & 6.72 & 0.5260 & 0.15 \\
Ileal pH & 6.22 & 6.48 & 6.95 & 6.97 & 0.2302 & 0.29 \\
& Cecal short chain fatty acid concentrations (mmol $/ \mathrm{kg})$ & \\
Acetic Acid & 42.6 & 39.8 & 40.0 & 38.8 & 0.9205 & 4.23 \\
Propionic Acid & 2.63 & 3.08 & 2.67 & 3.28 & 0.4980 & 0.35 \\
Butyric Acid & 10.2 & 8.81 & 8.81 & 8.86 & 0.8530 & 1.34
\end{tabular}

${ }^{1}$ Basal = basal diet; $\mathrm{BMD}=$ antibiotic diet; $3 \% \mathrm{OH}=$ fine oat hulls incorporated in the diet at $3 \%$; and FCOH $=$ free choice oat hulls. Standard error of the mean (SEM).

\section{Discussion}

Oat hulls represent the largest proportion of byproducts from the oat-milling operation [20]. If obtained from good quality oats, the $\mathrm{OH}$ may be as low as $25 \%$, but values ranging from $20 \%$ to $36 \%$ have been reported in the past [21-23]. Oat hulls disposal can be a serious concern for oat millers because of this large volume of waste (Girardet and Webster, 2011). The chemical composition of the $\mathrm{OH}$ used in the current study was similar to those reported by Garcia et al. [24], Jimenez-Monero et al. [8] and Mossami [25]. Compared to the basal and BMD diets, the inclusion of 3\% $\mathrm{OH}$ did not affect FI, BWG and FCR, although birds fed the 3\% OH diet had the numerically highest BWG and the best FCR. Hetland and Svihus [26] and Mossami [25] reported that the inclusion of 4\% OH increased FI without affecting the BWG of broiler chickens. The reason why FI was not affected in the current study could be because of the lower inclusion level of $\mathrm{OH}$. It should also be noted that the $\mathrm{OH}$ diet in the current study was formulated to be isocaloric and isonitrogenous with the basal and BMD diets, which was not the case in the studies of Hetland and Svihus [26] and Mossami [25]. Chickens would normally compensate for decreased nutrient concentration in diluted $\mathrm{OH}$ diets by increasing their FI. Similar to the current study, Garcia et al. (2019) did not observe any effect on growth performance when $3 \% \mathrm{OH}$ was fed to broiler chickens. Jimenez-Moreno et al. [8] did not observe any effect of $\mathrm{OH}$ included at $2.5,5.0$, or $7.5 \%$ on FI and BWG, although an improvement in FCR was observed. Compared to the FCOH group, birds fed $3 \% \mathrm{OH}, \mathrm{BMD}$, and Basal diets had higher BWG and better FCR throughout the study. During d 22 to 28 , birds that had access to FCOH consumed more feed compared to those fed 3\% OH, though this increase in FI intake did not result in better BWG and FCR. This suggested that birds that had access to $\mathrm{FCOH}$ consumed more $\mathrm{OH}$ at the expense of the basal diet during that period. To our knowledge, Kheravii et al. [12] was the only study in the literature that investigated FCOH in chickens. They reported that birds that had access to FCOH had lower FI and tended to have lower FCR compared to those that did not have access to FCOH. Although Kheravii et al. [12] did not report the quantity of $\mathrm{OH}$ consumed, the current study observed that birds that had access to FCOH consumed more than fourfold $\mathrm{OH}$ compared to those fed 3\% OH (2700 vs $600 \mathrm{~g} / \mathrm{bird})$. During the starter phase, access to FCOH did not have a negative effect on FCR. This shows that FCOH may be more beneficial to starter chicks. This is consistent with the report of Sadeghi et al. [27] that broiler chicks preferred to consume lower separate sources of insoluble fiber at younger ages of 1 to $14 \mathrm{~d}$. Kheravii et al. [12] also observed that improvement in growth performance due to FCOH was more pronounced in young broilers. During the grower and finisher phases, birds in the FCOH group consumed more $\mathrm{OH}$ at the expense of the nutritionally balanced basal diet, which resulted in nutrient dilution and less efficiency in converting feed to gains.

Compared to the basal and BMD diets, birds fed 3\% OH had similar carcass and breast muscle weights. However, birds fed 3\% $\mathrm{OH}$ had the numerical highest hot carcass weight $(7.9 \%$ higher than the basal diet), cold carcass (10.2\% higher than the basal diet) and breast muscle weights, which were significantly higher $(p \leq 0.05)$ when compared with the $\mathrm{FCOH}$ group. However, there were no significant differences in carcass yield (\% live weight). Lonkar et al. [28] reported that the inclusion 
of $2 \% \mathrm{OH}$ in broiler diet showed a significant improvement in ready-to-cook yield and a numerical improvement in carcass eviscerated and giblet yield. This has not been the case with high fiber inclusion levels. Shahin and Abdelazim [29] demonstrated that a high fiber diet ( $8 \%$ inclusion) suppressed carcass weight compared to low fiber (4\% inclusion). Mourao et al. [30] also indicated that broilers fed $5-10 \%$ citrus pulp and dehydrated pasture had lower carcass weights and carcass relative live weights due to a more developed gastrointestinal tract.

Our findings showed that birds that had access to $\mathrm{FCOH}$ had increased gizzard weight and tended to have increased cecal weight. This is consistent with the report of Kheravii et al. [12] that birds that had access to FCOH had heavier gizzards compared to those that did not have access. A diet containing $\mathrm{OH}$ would be retained longer in the gizzard due to being much lignified and more resistant to grinding as reported by Rogel et al. [31,32]. A large and well-developed gizzard would be able to completely grind feed particles and improve nutrient digestibility and utilization compared to smaller ones. This is consistent with the fact that birds in the FCOH consumed $2100 \mathrm{~g} / \mathrm{bird}$ more OH than those in the $3 \% \mathrm{OH}$ group, in the current study. There was no effect of $\mathrm{OH}$ on entire intestinal length and weight in the current study. Previous studies have shown that increased intestinal length is more associated with feeding soluble fiber than insoluble fiber. For example, Jimenez-Moreno et al. [9] reported longer intestines in chicks fed sugar beet pulp (containing soluble fiber) than those fed rice hulls (containing insoluble fiber). Similarly, Iji et al. [33] reported that broilers fed a higher soluble fiber type had greater intestinal weight. Oat hulls contained $535 \mathrm{~g} / \mathrm{kg}$ insoluble non-starch polysaccharides and no soluble non-starch polysaccharides were detected [12]. There was no effect of treatment on jejunal morphology in the current study. Similarly, Torki et al. [11] and Jimenez-Moreno et al. [9] did not detect any effect of $\mathrm{OH}$ inclusion on the jejunal villus height of the gastrointestinal tract of broilers. Kimiaeitalab et al. [34] also did not observe any effect of sunflower hull inclusion on the ileal mucosal morphology of broiler chickens. An increased jejunal villus height is indicative of a higher absorptive surface area of the jejunum. Previous studies have reported that feeding soluble fiber reduced intestinal villus height, while insoluble fiber did not $[27,33]$. Thus, it seems that the negative effect of dietary fiber on intestinal villus height reported in previous studies is more related to an increase in digesta viscosity, which is usually associated with soluble fiber.

Digesta $\mathrm{pH}$ can be an indicator of the proliferation of acid-intolerant pathogenic bacteria or the presence of SCFA. The current study did not observe any effects of $\mathrm{OH}$ on digesta $\mathrm{pH}$ and ceca SCFA. Similarly, Kimiaeitalab et al. [34] did not observe any effect of 3\% sunflower hull inclusion in diets for broilers or pullets on SCFA concentration, but observed $\mathrm{h}$ igher SCFA concentrations in pullets compared to broilers. Kheravii et al. [12] reported that broilers given FCOH had lower concentrations of acetic, propionic and valeric acid, but a higher concentration of succinic acid compared to those without access to FCOH. It should be noted that the study of Kheravii et al. [12] involved necrotic enteritis challenge, which could have stimulated the production of succinic acid, which was suggested to have immunomodulatory effects among the challenge birds. It has been reported that succinate or succinic acid increased pro-inflammatory cytokines such as interleukin -8 and interleukin- $1 \mathrm{~b}[35,36]$. Several factors may affect the concentrations and proportions of SCFA in birds and these include sites of fermentation in the gut (which changes with age), the type and amount of the fiber ingredient, microbiome composition, and the age of birds [37-39].

\section{Conclusions}

The inclusion of $3 \% \mathrm{OH}$ in diets for broiler chickens has the potential to improve growth performance and carcass weight. Oat hulls fed as free choice increased gizzard weight in broiler chickens but reduced FCR in the grower and finisher phases. There was no effect of $\mathrm{OH}$ incorporated in the diet at $3 \%$ or fed as free choice on jejunal morphology, digesta $\mathrm{pH}$ and cecal SCFA. Further research on the effect of different physical forms of $\mathrm{OH}$ on cecal microbiota is underway to elucidate the reason for the lack of effect on cecal SCFA. 
Author Contributions: Conceptualization, D.A.; methodology, D.A.; software, J.M. D.A.; validation, D.A., B.R., G.F. and J.M.; formal analysis, D.A.; investigation, D.A., J.M., G.F. and B.R.; resources, D.A.; data curation, D.A. and J.M.; writing - original draft preparation, D.A.; writing—review and editing, D.A., J.M., and B.R.; visualization, D.A.; supervision, D.A.; project administration, D.A. and J.M.; funding acquisition, D.A. All authors have read and agreed to the published version of the manuscript.

Funding: This project was funded by the Dalhousie University Start-Up Grant to Deborah Adewole.

Acknowledgments: This study was presented in part, at the Poultry Science Association (PSA) Annual Meeting 2019 Montreal, QC, Canada. The authors are grateful to Sarah MacPherson and Krista Budgell for animal care, to Jamie Fraser for diet production and to Rojman Khomayezi for analyzing the histological slides. The authors acknowledge Grain Millers, Saskatoon, SK, Canada for supplying the OH used in this study.

Conflicts of Interest: The authors declare no conflict of interest.

\section{References}

1. Chicken Farmers of Canada Annual Report. 2017. Available online: https://www.chickenfarmers.ca/wpcontent/uploads/2018/03/2017-Annual-Report-ENG-web-2.pdf (accessed on 6 April 2020).

2. Huyghebaert, G.; Ducatelle, R.; Van Immerseel, F. An update on alternatives to antimicrobial growth promoters for broilers. Vet. J. 2011, 187, 182-188. [CrossRef] [PubMed]

3. Ndou, S.P.; Tun, H.M.; Kiarie, E.; Walsh, M.C.; Khafipour, E.; Nyachoti, C.M. Dietary supplementation with flaxseed meal and oat hulls modulates intestinal histomorphometric characteristics, digesta-and mucosa-associated microbiota in pigs. Sci. Rep. 2018, 8, 1-15. [CrossRef] [PubMed]

4. Kim, J.C.; Mullan, B.P.; Hampson, D.J.; Pluske, J.R. Addition of oat hulls to an extruded rice-based diet for weaner pigs ameliorates the incidence of diarrhoea and reduces indices of protein fermentation in the gastrointestinal tract. Br. J. Nutr. 2008, 99, 1217-1225. [CrossRef] [PubMed]

5. Jiménez-Moreno, E.; González-Alvarado, J.M.; Lázaro, R.; Mateos, G.G. Effects of type of cereal, heat processing of the cereal, and fiber inclusion in the diet on gizzard $\mathrm{pH}$ and nutrient utilization in broilers at different ages. Poult. Sci. 2009, 88, 1925-1933. [CrossRef]

6. den Besten, G.; van Eunen, K.; Groen, A.K.; Venema, K.; Reijngoud, D.J.; Bakker, B.M. The role of short-chain fatty acids in the interplay between diet, gut microbiota, and host energy metabolism. J. Lipid. Res. 2013, 54, 2325-2340. [CrossRef]

7. Cherrington, C.A.; Hinton, M.; Pearson, G.R.; Chopra, I. Short-chain organic acids at pH 5.0 kill Escherichia coli and Salmonella spp. without causing membrane perturbation. J. Appl. Bacteriol. 1991, 70, 161-165. [CrossRef]

8. Jiménez-Moreno, E.; Frikha, M.; de Coca-Sinova, A.; García, J.; Mateos, G.G. Oat hulls and sugar beet pulp in diets for broilers 1. Effects on growth performance and nutrient digestibility. Anim. Feed Sci. Technol. 2013, 182, 33-43. [CrossRef]

9. Jiménez-Moreno, E.; Frikha, M.; de Coca-Sinova, A.; Lázaro, R.P.; Mateos, G.G. Oat hulls and sugar beet pulp in diets for broilers. 2. Effects on the development of the gastrointestinal tract and on the structure of the jejunal mucosa. Anim. Feed Sci. Technol. 2013, 182, 44-52. [CrossRef]

10. Jiménez-Moreno, E.; González-Alvarado, J.M.; de Coca-Sinova, A.; Lázaro, R.P.; Cámara, L.; Mateos, G.G. Insoluble fiber sources in mash or pellets diets for young broilers. 2. Effects on gastrointestinal tract development and nutrient digestibility. Poult. Sci. 2019, 98, 2531-2547. [CrossRef]

11. Torki, M.; Schokker, D.; Duijster-Lensing, M.; Van Krimpen, M.M. Effect of nutritional interventions with quercetin, oat hulls, $\beta$-glucans, lysozyme and fish oil on performance and health status related parameters of broilers chickens. Br. Poult. Sci. 2018, 59, 579-590. [CrossRef]

12. Kheravii, S.K.; Swick, R.A.; Choct, M.; Wu, S.B. Effect of oat hulls as a free choice feeding on broiler performance, short chain fatty acids and microflora under a mild necrotic enteritis challenge. Anim. Nutr. 2018, 4, 65-72. [CrossRef] [PubMed]

13. Wilkinson, S.J.; Selle, P.H.; Bedford, M.R.; Cowieson, A.J. Separate feeding of calcium improves performance and ileal nutrient digestibility in broiler chicks. Anim. Prod. Sci. 2014, 54, 172-178. [CrossRef]

14. Canadian Council on Animal Care. Guidelines on: The Care and Use of Farm Animals in Research, Teaching and Testing; Canadian Council on Animal Care: Ottawa, ON, Canada, 2009.

15. National Research Council. Nutrient Requirements of Poultry, 9th ed.; The National Academies Press: Washington, DC, USA, 1994. 
16. AOAC. Official Methods of Analysis, 15th ed.; Association of Official Analytical Chemists: Washington, DC, USA, 1990.

17. Goering, H.K.; Van Soest, P.J. Forage Fiber Analyses: Apparatus, Reagents, Procedures, and Some Applications; Agricultural Research Service, United States Department of Agriculture: Washington, DC, USA, 1970; Volume 379.

18. AOAC. Official Methods of Analysis of AOAC International, 18th ed.; AOAC Int.: Gaithersburg, MD, USA, 2005.

19. Shojadoost, B.; Vince, A.R.; Prescott, J.F. The successful experimental induction of necrotic enteritis in chickens by Clostridium perfringens: A critical review. Vet. Res. 2012, 43, 74. [CrossRef] [PubMed]

20. Girardet, N.; Webster, F.H. Oats: Chemistry and Technology, 2nd ed.; Webster, F., Ed.; Academic Press: Cambridge, MA, USA; American Associate of Cereal Chemists International: Saint Paul, MN, USA, 2016; pp. 301-319.

21. Hutchinson, J.B.; Kent, N.L.; Martin, H.F. The kernel content of oats: Comparison of kernel content and thousand kernel weight for winter and spring varieties. J. Natl. Inst. Agric. Bot. 1953, 6, 443-453.

22. Salo, M.L.; Kotilainen, K. On the carbohydrate composition and nutritive value of some cereals. Agric. Food Sci. 1970, 42, 21-29. [CrossRef]

23. Welch, R.W.; Hayward, M.V.; Jones, D.I.H. The composition of oat husk and its variation due to genetic and other factors. J. Sci. Food Agric. 1983, 34, 417-426. [CrossRef]

24. García, J.; Fondevila, G.; Cámara, L.; Scappaticcio, R.E.; Aguirre, L.; Mateos, G.G. Influence of egg weight and inclusion of oat hulls in the diet on digestive tract traits and growth performance of brown pullets reared under stress conditions. Poult. Sci. 2019, 98, 5767-5777. [CrossRef]

25. Mossami, A. Effects of Different Inclusions of Oat Hulls on Performance, Carcass Yield and Gut Development in Broiler Chickens. Master's Thesis, Swedish University of Agricultural Science, Uppsala, Sweden, 2011.

26. Hetland, H.; Svihus, B. Effect of oat hulls on performance, gut capacity and feed passage time in broiler chickens. Br. Poult. Sci. 2001, 42, 354-361. [CrossRef]

27. Sadeghi, A.; Toghyani, M.; Gheisari, A. Effect of various fiber types and choice feeding of fiber on performance, gut development, humoral immunity, and fiber preference in broiler chicks. Poult. Sci. 2015, 94, 2734-2743. [CrossRef]

28. Lonkar, V.; Ranade, A.; Kulkarni, V.; Pathak, C. Inclusion of oat hulls as a source of insoluble fiber in broiler diet-An alternative to AGP. Int. J. Livest. Res. 2018, 10, 252-264. [CrossRef]

29. Shahin, K.A.; Abdelazim, F. Effects of breed, sex and diet and their interactions on carcass composition and tissue weight distribution of broiler chickens. Arch. Tierz. 2005, 6, 612-626. [CrossRef]

30. Mourão, J.L.; Pinheiro, V.M.; Prates, J.A.M.; Bessa, R.J.B.; Ferreira, L.M.A.; Fontes, C.M.G.A.; Ponte, P.I.P. Effect of dietary dehydrated pasture and Citrus pulp on the performance and meat quality of broiler chickens. Poult. Sci. 2008, 87, 733-743. [CrossRef] [PubMed]

31. Rogel, A.M.; Annison, E.F.; Bryden, W.L.; Balnave, D. The digestion of wheat starch in broiler chickens. Aust. J. Agric. Res. 1987, 38, 639-649. [CrossRef]

32. Rogel, A.M.; Balnave, D.; Bryden, W.L.; Annison, E.F. Improvement of raw potato starch digestion in chickens by feeding oat hulls and other fibrous feedstuffs. Aust. J. Agric. Res. 1987, 38, 629-637. [CrossRef]

33. Iji, P.A.; Saki, A.A.; Tivey, D.R. Intestinal development and body growth of broiler chicks on diets supplemented with non-starch polysaccharides. Anim. Feed Sci. Technol. 2001, 89, 175-188. [CrossRef]

34. Kimiaeitalab, M.V.; Cámara, L.; Mirzaie Goudarzi, S.; Jiménez-Moreno, E.; Mateos, G.G. Effects of the inclusion of sunflower hulls in the diet on growth performance and digestive tract traits of broilers and pullets fed a broiler diet from zero to $21 \mathrm{~d}$ of age. A comparative study. Poult. Sci. 2017, 96, 581-592. [CrossRef]

35. Graham, L.S.; Krass, L.; Zariffard, M.R.; Spear, G.T.; Mirmonsef, P. Effects of succinic acid and other microbial fermentation products on HIV expression in macrophages. BioRes. Open Access 2013, 2, 385-391. [CrossRef]

36. Tannahill, G.M.; Curtis, A.M.; Adamik, J.; Palsson-McDermott, E.M.; McGettrick, A.F.; Goel, G.; Frezza, C.; Bernard, N.J.; Kelly, B.; Foley, N.H.; et al. Succinate is an inflammatory signal that induces IL-1 $\beta$ through HIF-1 $\alpha$. Nature 2013, 496, 238-242. [CrossRef]

37. Meimandipour, A.; Soleimanifarjam, A.; Azhar, K.; Hair-Bejo, M.; Shuhaimi, M.; Nateghi, L.; Yazid, A.M. Age effects on short chain fatty acids concentrations and $\mathrm{pH}$ values in the gastrointestinal tract of broiler chickens. Archiv Für Geflügelkunde 2011, 75, 164-168. 
38. Sun, B.; Hou, L.; Yang, Y. Effects of altered dietary fiber on the gut Microbiota, short-chain fatty acids and cecum of chickens during different growth periods. Anim. Sci. Zool. 2020. [CrossRef]

39. Walugembe, M.; Hsieh, J.C.F.; Koszewski, N.J.; Lamont, S.J.; Persia, M.E.; Rothschild, M.F. Effects of dietary fiber on cecal short-chain fatty acid and cecal microbiota of broiler and laying-hen chicks. Poult. Sci. 2015, 94, 2351-2359. [CrossRef] [PubMed]

C 2020 by the authors. Licensee MDPI, Basel, Switzerland. This article is an open access article distributed under the terms and conditions of the Creative Commons Attribution (CC BY) license (http://creativecommons.org/licenses/by/4.0/). 